\title{
A Study Case for Relationship between Skeletal Anomalies and Posture
}

Alketa Qafmolla

PhD Prof. Dr. DDS

Ruzhdie Qafmolla

Faculty of Medicine Dental, Tirana, Albania

\section{Abstract}

The concept that good health is connected in some way with posture is not new to the medical contemporary philosophy, because several authors have demonstrated an association between the morphology of the cervical column, the head and neck posture and mandible position. Different authors have highlighted a correlation between the morphology of the cervical column and the face dimensions. Positive correlations are found between cervico-cefalic posture and the anterior level of the dent-alveolar mandible and maxilla. For our study the main objective was to discover the relationship between oral anomalies and posture, analyzing the cervical and spinal pathologies at patients with malocclusion. In this study were involved 200 patients aged 516 years old with clinical anomalies, presented for 2006 - 2011 period in Orthodontic Department of Medical Dentistry Hospital. Patients were divided in four groups based on their oral anomalies. We performed clinical and radiological examinations, evaluating the morphology of the cervical column. Cephalometric measurements were performed in order to evaluate the cranial basis angle, the vertical craniofacial dimensions, and the sagittal relation of the jaws with each other and with the anterior and posterior cranial bases. Panoramic x-rays were also taken for each individual included at the study. Our study has demonstrated that patients had a higher prevalence of postural pathologies (32\%) compared to the control group $(3 \%)$, and in this change was find a significant statistically value about $\mathrm{p}<0,001$. Also, the most prevalent postural anomalies were fusion C2-C3, kyphosis and lodrosis and less scoliosis.

Keywords: Skeletal Anomalies, Posture Morphology, Craniofacial Dimensions, Kyphosis, Scoliosis 


\section{Introduction}

Malocclusion is a pathology that affects the teeth - jawbone - face apparatus. A causal relation may exist between craniofacial and occlusion morphology, especially the posterior, anterior and lateral positions of the mandible and abnormal posture of the body (1). The concept that good health is connected in some way with posture is not new to the medical contemporary philosophy. Dental health, too, may have an impact in general health. Recent research suggests that oral anomalies may influence the posture in certain individuals. Several authors have demonstrated an association between the morphology of the cervical column, the head and neck posture and mandible position (1-5). Solow et al. have highlighted that there is a correlation between the morphology of the cervical column and the face dimensions (3). Positive correlations are found between cervico-cefalic posture and the anterior level of the dento-alveolar mandible and maxilla, as well as of the tendencies of the upper and lower oclussal planes $(6,7)$. The mandible position may change continuously depending on head and neck position (7-9). The patients with different dental anomalies and especially at the skeletal level, for example skeletal dental anomaly of the IInd IIIrd class, the deep bite and the unilateral or bilateral cross bite, show different postural problems, such as the fusion of the C2-C3 vertebras, scoliosis, lordosis and kyphosis, etc. The time when symptoms appear depends on several factors, including the posture duration and individual adaption ability $(10,11)$. The aim of our study was to discover the relationship between oral anomalies and posture, by analyzing the cervical and spinal pathologies in patients with specific malocclusions in comparison with individuals with normal occlusion and craniofacial morphology (control group).

\section{Material and methods}

This was prospective study which included 200 patients aged 5-16 years old with clinical anomalies at the teeth - jawbone - face apparatus, who presented at the Orthodontics Unit at the University Hospital Center, in Tirana, Albania for 2006 to 2011 period. 200 age- and sex-matched individuals with normal occlusion and craniofacial morphology were included as a control group. Patients were included if they fulfilled the following criteria: had not received any orthodontic treatment during childhood; having at least 24 permanent teeth; and with no congenital craniofacial anomalies. Controls were included if they fulfilled the following criteria: having almost normal occlusion with no need for orthodontic treatment; having normal sagittal or vertical relation of the jaws, evaluated by lateral radiography for each individual. Patients were divided in four groups based on their oral anomalies:

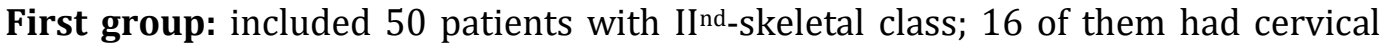
problems, of whom 10 patients had C2-C3 fusion, and 6 patients had deficiencies of the $\mathrm{C} 1$ posterior arch.

Second group: included 50 patients with deep bite: 23 patients had fusion problems at C2-C3. 
Third group: included 50 patients with IIIrd skeletal class: 11 of them had posture problems, 2 others patients had scoliosis and 9 patients kyphosis.Fourth group: included 50 patients with unilateral cross bite, 14 of them had scoliosis.

We performed clinical and radiological examinations, evaluating the morphology of the cervical column. Cephalometric measurements were performed in order to evaluate the cranial basis angle, the vertical craniofacial dimensions, and the sagittal relation of the jaws with each other and with the anterior and posterior cranial bases. Panoramic x-rays were also taken for each individual included at the study.

\section{Statistical analysis}

The data were analyzed with SPSS 20.0 package. The categorical variables are shown in tables with absolute/relative frequencies. The distribution test of the continual variables was done with Anderson - Darling method. The $\mathrm{X}^{2}$ test with Yates correction was used for the comparison of proportions between variables. Significance level was set at $\mathrm{p}<0.05$.

\section{Results}

The average age of the patients was 11.9 years with standard deviation $\mathrm{SD} \pm 3.4$ years (range 5-16 year), while the average age of the control group was 10.4 years with $\mathrm{SD} \pm 3.4$ years (range 5-16 years). There are not statistically significant changes between patients and control group with regard to age $(\mathrm{p}=0.7) .142$ patients $(71.5 \%)$ and 142 individuals of the control group were females, while $58(28.7 \%)$ patients and 58 individuals of the control group were males. The demographic characteristics of the patients and control groups are given in table 1.

Table 1. Demographic characteristics of the patients and control group

\begin{tabular}{lll}
\multicolumn{1}{l}{ Group } & & $n(\%)$ \\
\hline Females $n(\%)$ & $142(71,3)$ & 142 \\
& & $(71.3)$ \\
Males $n(\%)$ & $58(28,7)$ & 58 \\
& & $(28.7)$ \\
Age in years & $11,9(3,4)$ & 10,4 \\
mean (SD) & & $(3,4)$ \\
Age in each group mean (SD) & & \\
Ilnd skeletal class (n=50) & $11,5(3,2)$ & 11,7 \\
& & $(2,8)$ \\
Deep bite (n=50) & $11,0(2,9)$ & 11,7 \\
& & $(2,8)$
\end{tabular}


IIIrd skeletal class $(n=50) \quad 11,3(3,1)$

10,9

Cross bite $(n=50)$

$10,5(2,7$

In total the postural and cervical pathologies were manifested in 64 (32\%) of patients, compared to $6(3 \%)$ individuals of the control group $(\mathrm{p}<0.001)$. The postural anomalies for each group of patients are shown in table 2.Table 2. The prevalence of cervical-spinal in patients with different types of mal-occlusion

\begin{tabular}{ll}
\hline Group & $n(\%)$ \\
\hline & \\
First group: Ilnd skeletal class & $34(68 \%)$ \\
Normal & $16(32 \%)$ \\
With postural anomalies & $10(20 \%)$ \\
$\quad$ Fusion & $6(12 \%)$ \\
$\quad$ Lordosis & \\
Second group: deep bite & $27(54 \%)$ \\
Normal & $23(46 \%)$ \\
With postural anomalies & $39(78 \%)$ \\
Third group: IIIrd skeletal class & $11(22 \%)$ \\
Normal & $9(18)$ \\
With postural anomalies & $2(4 \%)$ \\
$\quad$ Kyphosis & $36(72 \%)$ \\
Scoliosis & $14(28 \%)$ \\
Fourth group: Cross bite & \\
Normal & \\
With postural anomalies & \\
\hline
\end{tabular}

\section{Discussions}

In our study we included 200 patients and 200 age- and sex-matched controls. Selection of this age group was based on an orthodontic rationale, since patients with skeletal anomalies are still growing at this age, and thereby they will respond well to orthodontic therapy. One of the postural pathologies observed in our study was idiopathic scoliosis (8\%). According to different authors, this postural pathology was shown in children between 10 years old and skeletal maturation age and includes almost $80 \%$ of all idiopathic scoliosis cases $(12,13)$. It affects girls more than boys (14), and the prevalence is estimated to be between $2-4 \%$ of children $10-16$ years old. This female preponderance may be due to hormonal changes, which appear earlier in females (15-17). Many authors suggest that there is a significant association between the II ${ }^{\text {nd }}$ IIIrd class of mal-occlusion and body posture (18-20). Oclussal anomalies may account as risk factors in as much as $30 \%$ of patients with postural problems. In accordance with these authors, our study demonstrated that patients had a higher prevalence of postural pathologies (32\%) compared to the control group 
(3\%), and this change was statistically significant $(\mathrm{p}<0,001)$. Children with II $^{\text {nd }}$ class skeletal malocclusion have shown an important extension of the cervical lordosis compared to patients with Ist skeletal class and keep the head well in front $(6,22)$. The prevalence of lordosis in our study was $37 \%$. The research of Ben-Bassat et al has shown that patients with scoliosis have more asymmetry at the sagittal and transversal dimensions, compared to normal individuals (23). Patients with scoliosis have a greater prevalence of the deviation of the lower median line (posterior cross bite). More studies from other authors shown the correlation that exists between cervical-cephalic posture and craniofacial morphology $(4,24)$. Positive correlation was demonstrated between cervico-cefalik posture and the anterior dento-alveolar dimension of the mandible and maxilla, as well as the inclination of the inferior and superior occlusal plan $(3,4)$.

\section{Conclusions}

The results of our study show that patients had a higher prevalence of postural pathologies compared to the control group, and this change was statistically significant. The most prevalent postural anomalies were fusion of C2 - C3, kyphosis and lordosis and less scoliosis.

\section{References}

[1] Sonnesen L, et al. Cervical column morphology related to head posture, cranial base angle and condylar malformation. European Journal of Othodontics 2007,29:398-403;

[2] Solow B, Sonnesen J. Head posture and malocclusions. European Journal Orthodontics 1998,20:685-693.

[3] Solow B, Tollgern A. Dentolveolar morphology in relation to craniocervical posture. Angle Orthodoncie 1977,47:157-164

[4] Bacon W, Turlot JC,Blaise M. La reproductibilite de la posture naturelle de la tete e soon implication dans l'organisation del' architecture cranio-faciale. Reviste Othopedic Dento Faciale 1989,22:277-286.

[5] Attilio M, et al.Evaluation of cervical posture of children in skeletal class and crania 2005,23:219- 228.

[6] Gadotti JC, et al. Preliminary report on hard posture and muscle activity in subjects with 1-st and 2- nd class. Journal Oral Rehabilitation 2005,32:794799.

[7] Chaphman R J, et al. Occlusal contact variation with changes in head position. International Journal Prosthodontics 1991,4 :377-381.

[8] Martensmeir I, Dietrich P. Which correlations between cervical posture and malocclusion. Fortsehr Kiefrirthopedic 1992,52:26-32.

[9] Woda A, et al.Critical reviews in Oral Biology and Medicine J. Oral Biology and Medicine 2001,12:166-178.

[10] Levinkind M. Dental Posture Interactions for Optimal Health. Journal Orthodontic May 2003,88:1-4. 
[11] Huggare J, et al. Head posture and cervico vertebral anatomy as mandibular growth predictors. European Journal Orthopedy 1994,16: 175-180.

[12] Alexander RG. The effects on tooth position and Maxillofacial vertical growth during treatment of scoliosis with Milwauke brace. American Journal Orthodontic 1966,52:161-189.

[13] Weinstein SL, et al. Turek's Orthopedics principles and their application. 5-th edition, Philadelphia Journal Lippincott 1994.

[14] Roach J.W Adolescent idiopatic scoliosis :current concepts orthopedic clinical. North America 1999,30:353-365.

[15] Amat P. Orthopedie dento-faciale fonde sur les fits marotte d'universitare au indensensable outiechinque quoteidien. Reviste ortho dento faciale 2006,40:421-451.

[16] Robin G.GC .The aethiology of idiopathic scoliosis. A review of a centery of research . Boca Ratan. Fla 1990.

[17] Links $P$, et al. An evaluation on dentofacial changes accompanying scoliosis therapy with a modifies Milwaukee brace. Orthodontic 1982,53:697-704.

[18] Litton, Ackerman. Isacsson , Spariro, A genetic study of III-rd class malocclusion. American Journal orthodoncy 1970,58:565-577.

[19] Subtelny JD. Malocclusion orthodontic corrections and orofacial muscle adaption. Angle orthod 1970,40:170-201.

[20] Suzaki,M.Naruse, et al. Measurement of lateral lords exerted on maxillofacial region by habitual posture. Buletin Tokyo Dental College 2002,43:69-74.

[21] Annicchiarico.C. Las diffusion cranio-cervico mandibolario cause sintomi e rimendi. Estratto da Medicina Metropolitana ,Palermo n:1,2009.

[22] Solow B, et al. Cervical and Craniocervical posture as predictars of craniocervical posture. American Journal Orthodoncy Dentofacial Orthopedic 1992,101:449-458

[23] Ben Bassat Y, et al. Occlusal patterns in patients with idiopathic scolisios. American Journal Dentofacial orthopedic 1991,72:653-656.

[24] Attilio. M. Caputi S, et al . Evaluation of cervical posture of children in skeletal class and crania J.Crania 2005,23:219-228. 